\title{
Alexithymia: a relevant psychological variable in near-fatal asthma
}

\author{
J. Serrano*, V. Plaza*, B. Sureda\#, J. de Pablo\#, C. Picado", S. Bardagí ${ }^{+}$, J. Lamela ${ }^{\S}$ \\ and J. Sanchis*, on behalf of the Spanish High Risk Asthma Research Group
}

\begin{abstract}
Alexithymia is a psychological trait characterised by difficulty in perceiving and expressing emotions and body sensations. Failure to perceive dyspnoea could lead alexithymic asthmatics to underestimate the severity of an asthma exacerbation, and thereby increase the risk of developing a fatal or near-fatal asthma (NFA) attack. The objective of the present study was to determine the prevalence of alexithymia in NFA patients and to analyse their clinical characteristics.
\end{abstract}

Alexithymia was assessed using the Toronto Alexithymia Scale in this multicentric prospective observational study. From 33 Spanish hospitals, 179 NFA patients and 40 non-NFA patients, as a control group, were enrolled.

There was a higher proportion of alexithymia in the NFA group than in the non-NFA group (36 versus 13\%). Patients with NFA and alexithymia were older than the rest of the NFA group, and had a lower level of education, a higher level of psychiatric morbidity, a higher proportion of severe persistent asthma and a greater number of prior very severe asthma exacerbations (49 versus $\mathbf{2 7 \%}$ ). Alexithymia, severe persistent asthma and a low level of education were identified as independent variables related to repeated very severe asthma exacerbations.

The results show that alexithymia is more frequent in near-fatal asthma patients compared to the rest of asthmatics and is associated with recurrent very severe asthma exacerbations.

KEYWORDS: Affective symptoms, asthma/psychology, near-fatal asthma, perceptual distortion, status asthmaticus

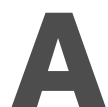

lthough asthma is frequently a mild disease, under certain circumstances it can develop into extremely severe and occasionally fatal crises. The group of lifethreatening asthma exacerbations is known as near-fatal asthma (NFA) [1]. A determining factor in the development of many of these episodes is a surprising delay in seeking medical assistance [2, 3]. Several authors have suggested that, in certain patients, this could be related to a deficit in the perception of symptoms, such as dyspnoea, or to a lack of response to the hypoxaemia and/or hypercapnia produced during a severe asthma exacerbation [4, 5]. Patients may subsequently underestimate the severity of the attack and delay beginning recommended treatment until their condition becomes critical. Indeed, recent studies have shown that patients with reduced perception of dyspnoea need more frequent medical attention and hospitalisation than other asthmatics, and have more fatal asthma and NFA attacks [6]. Some authors, moreover, have associated reduced perception of dyspnoea with certain psychological characteristics and psychiatric disorders frequently observed in NFA patients $[7,8]$. As a result, the affective component of dyspnoea, the component that evokes distress and motivates behaviour, is considered a key aspect in asthmatics' response to exacerbations of their disease [9].

Alexithymia is a psychological trait characterised, among other manifestations, by a difficulty in recognising body sensations and describing emotions [10]. Prevalence oscillates in the range of $8-19 \%$ in the general population, but it can be higher in individuals with certain chronic diseases [11]. In the case of asthma, the few studies carried out to date show lower levels of anxiety, dyspnoea and tachypnoea during exacerbations in alexithymic asthmatics [12]. These findings suggest the possibility that this psychological cluster could blunt the perception of the severity of the asthma exacerbation and, therefore, play a role in the delay in seeking medical help observed in some NFA patients. Since data on the relationship between NFA and alexithymia have not been investigated to date, the present study was designed to determine the frequency of alexithymia in NFA patients and describe its
AFFILIATIONS

*Departament de Pneumologia,

Hospital de la Santa Creu i Sant Pau,

\#Servei de Psiquiatria.

"Pneumologia i Al.lergia

Respiratòria, Hospital Clínic,

${ }^{+}$Hospital de Mataró, Barcelona, and

${ }^{\S}$ Hospital Cristal-Piñor, Orense,

Spain

CORRESPONDENCE

J. Serrano

Servicio de Neumología

Clínica Juaneda

Company 20

07014 Palma

Illes Balears

Spain

Fax: 34971737530

E-mail: jserrano@separ.es

Received:

January 232005

Accepted after revision:

March 102006

SUPPORT STATEMENT

This study was supported by a grant from the Fundación Española de Patología Respiratoria (Barcelona, Spain; 1996), the Societat Catalana de Pneumologia (Barcelona, Spain; 1998) and the Sociedad Española de Neumología y Cirugía Torácica (Barcelona, Spain; 1998) of the RedRespira-Instituto de Salud Carlos III-Red Temática de Investigación Cooperativa (Madrid, Spain)-03/11.

European Respiratory Journa Print ISSN 0903-1936

Online ISSN 1399-3003 
clinical characteristics, in order to analyse a possible role in severe asthma exacerbations. Some of the results of the study have been previously reported in abstract form [13].

\section{METHODS}

\section{Study design}

A detailed description of the method used has been published previously [14]. Briefly, a descriptive prospective multicentric study was carried out in 33 hospitals in Spain. These centres cover a population of $15,000,000$ inhabitants, i.e. $40 \%$ of the total Spanish population. Patients were enrolled in the study from April 1997 until March 1999.

\section{Patients}

Asthmatics of both sexes aged $\geqslant 15$ yrs were included prospectively and consecutively. All patients fulfilled the American Thoracic Society diagnostic criteria for asthma [15]. An NFA episode was defined as a severe asthma exacerbation accompanied by at least one of the following: 1) respiratory arrest; 2) requirement for mechanical ventilation; and 3) hypercapnia with an arterial carbon dioxide tension $\left(\mathrm{Pa}_{\mathrm{a}} \mathrm{CO}_{2}\right)$ of $>6.65 \mathrm{kPa}$ and/or acidosis with a $\mathrm{pH}$ of $<7.30$. Exclusion criteria were concomitant acute severe diseases such as heart disease or pulmonary embolism suspected of inducing the exacerbation. The control group included asthma patients of similar age, sex and pulmonary function, without a prior history of NFA episodes. For every level of severity of asthma (according to Global Initiative for Asthma (GINA) [16] guidelines), consecutive asthma patients were selected from the outpatient clinic of four participant hospitals.

\section{Variables measured}

All patients completed a 72-item enrolment form specifically designed for the present study. This information was divided into five areas: 1) demographic and sociocultural variables; 2) clinical and functional characteristics of asthma, according to the GINA classification [16]; 3) clinical condition of the patient at hospital admission; 4) in-hospital progression of the NFA attack; and 5) spirometric and immunological studies. A patient was considered to have previously experienced a very severe asthma exacerbation when the clinical record reported prior mechanical ventilation, respiratory failure with acidosis $(\mathrm{pH}<7.30)$ and/or hypercapnia $\left(\mathrm{Pa}_{1} \mathrm{CO}_{2}>6.65 \mathrm{kPa}\right)$ or intensive care unit admission for an asthma exacerbation.

\section{Level of education}

Information about educational level was obtained by asking the patients to state their highest level of schooling attained. The possible answers were: 1) basic education: $<8$ yrs of schooling; 2) primary education: $\geqslant 8$ yrs of primary school, but incomplete or no secondary schooling; or 3) intermediate and higher education: completion of secondary school, professionallevel coursework or university studies.

\section{Psychometric tests}

The Toronto Alexithymia Scale (TAS) [17], a self-administered psychological questionnaire, was used to detect alexithymia. The validated Spanish version of this test (TAS-26) [18] consists of 26 items that explore the difficulty in identifying, distinguishing and describing sensations and emotions, the reduced capacity for imagination and externally orientated thinking, grouped in four subscales (IDE: difficulty identifying feelings, COM: difficulty communicating feelings, EOT: externally oriented thinking, and IMG: ability to fantasise). Patients with scores of $\geqslant 74$ were considered alexithymic. Psychiatric disorder was determined from a separate self-reported questionnaire, the 28-item version of the General Health Questionnaire (GHQ) [19], also validated in its Spanish version [20]. This test provides general information about anxiety, depression, somatic symptoms and social dysfunction. A score of $\geqslant 7$ was considered indicative of psychiatric disorder.

\section{Data collection and statistical analysis}

All data collected were forwarded to the coordinating centre and systematically checked. Additional information was requested from the researcher who had administered the questionnaire in cases of incomplete or unclear data. The information was computerised using a double manual process.

A descriptive analysis of the sample was performed for all of the variables. Values were expressed as mean \pm SD or percentages. Medians were used for data with a non-Gaussian distribution (assessed using the Kolmogorov-Smirnov test). The results were compared between groups of NFA patients with or without alexithymia. Quantitative variables were analysed using the unpaired t-test or Mann-Whitney U-test, depending on their distribution. Qualitative variables were analysed using the Chi-squared test or Fisher's exact test, as necessary. Differences were considered significant at $\mathrm{p}$-values of $<0.05$. Logistic regression analysis was performed to control for possible confounding factors when measuring the influence of alexithymia in patients with a prior episode of very severe asthma exacerbation. Patient age was introduced as a continuous independent variable; sex, presence or absence of psychiatric disorder, and severity of asthma (severe persistent asthma as compared with moderate, mild or intermittent asthma [16]) were included as dichotomous variables, and educational level as a categorical variable with three levels (basic, primary, and intermediate or higher education).

\section{RESULTS}

Over the 24 months of data collection, 228 NFA episodes were recorded. Twelve patients who did not fulfil the study criteria were excluded. Three patients experienced a second NFA episode during the study period. In order to simplify the statistical analysis, the information related to this second attack was not included. Of the 213 remaining patients, 178 completed both the TAS and GHQ questionnaires, and one completed only the TAS questionnaire. Severe neurological consequences of the crises (four patients) and inability to understand the questions were the most frequent causes of incomplete questionnaires. Finally, data for the 179 NFA patients who successfully completed the TAS questionnaire were analysed. For the control group, a total of 40 patients were enrolled. Table 1 summarises the demographic variables and the clinical and functional characteristics observed in the NFA and non-NFA groups. No significant differences were found between groups for age, sex, spirometric data or severity of asthma. However, the proportion of patients with alexithymia was significantly higher in the NFA group (36\%) than in the non-NFA group (13\%). 


\begin{tabular}{|c|c|c|c|c|}
\hline \multirow[t]{2}{*}{ TABLE 1} & \multicolumn{4}{|c|}{$\begin{array}{l}\text { Demographic, asthma severity and spirometric } \\
\text { data observed in the near-fatal asthma (NFA) } \\
\text { and non-NFA groups }\end{array}$} \\
\hline & & NFA & Non-NFA & p-value \\
\hline \multicolumn{2}{|l|}{ Subjects $n$} & 179 & 40 & \\
\hline \multicolumn{2}{|l|}{ Age yrs } & $50.4 \pm 19.2$ & $48.4 \pm 18.7$ & NS \\
\hline \multicolumn{2}{|l|}{ Male } & 41 & 35 & NS \\
\hline \multicolumn{2}{|c|}{ Severe persistent asthma ${ }^{\#}$} & 52 & 47 & NS \\
\hline \multicolumn{2}{|c|}{ Moderate persistent asthma\# } & 42 & 42 & NS \\
\hline \multicolumn{2}{|c|}{ Mild persistent asthma\# } & 3 & 8 & NS \\
\hline \multicolumn{2}{|c|}{ Intermittent asthma ${ }^{\#}$} & 3 & 3 & NS \\
\hline \multicolumn{2}{|c|}{ FEV $1 \%$ pred } & $73 \pm 24$ & $78 \pm 24$ & NS \\
\hline \multicolumn{2}{|c|}{ Alexithymic patients } & 36 & 13 & 0.004 \\
\hline \multicolumn{5}{|c|}{$\begin{array}{l}\text { Data are presented as mean } \pm \text { SD or percentage. FEV } 1 \text { : forced expiratory } \\
\text { volume in one second; \% pred: percentage of the predicted value; NS: } \\
\text { nonsignificant. }{ }^{\#} \text { : classification from Global Initiative for Asthma (GINA; 1995) } \\
\text { [16]. }\end{array}$} \\
\hline
\end{tabular}

Table 2 displays the sociodemographic characteristics and asthma background of the 64 alexithymic NFA patients and the 115 nonalexithymic NFA patients. As shown, the alexithymic NFA patients were older, had a lower level of education ( $28 \%$ had received only basic schooling), tended to suffer more severe persistent disease, had a higher percentage of prior hospitalisations for asthma (in the past 12 months, $44 \%$ of alexithymic NFA patients had been hospitalised versus $23 \%$ of the nonalexithymic patients), and had experienced more prior episodes of very severe asthma exacerbations (49 versus $27 \%$ ) than the nonalexithymic patients. Use of both inhaled and oral corticosteroids was also significantly higher in the alexithymic NFA group. Spirometric data were similar in both groups. The alexithymic NFA patients also showed a higher proportion of psychiatric morbidity than the nonalexithymic patients. Table 3 shows the results of the logistic regression analysis used to study the influence of alexithymia on the development of repeated very severe asthma exacerbations. After controlling for age, sex, level of education, presence of psychiatric disorder and asthma severity as possible confounding factors, the relative risk of having suffered a very severe asthma exacerbation previously in the alexithymic patients was 2.175 (95\% confidence interval (CI) 1.002-4.721; $\mathrm{p}=0.049)$.

Table 4 shows the clinical, functional and analytical observations on hospital admission, as well as the pre-admission variables and patient course. No significant differences were found between alexithymic and nonalexithymic NFA patients for the following variables: 1) delay between onset of attack and arrival at the hospital; 2) means of transport to the hospital; 3) person who decided to seek medical attention for the patient; and 4) degree of compliance with the asthma action plan for self-management. The functional variables on admission, however, showed that alexithymic NFA patients exhibited better gas exchange and less need for mechanical ventilation. Clinical variables on admission (respiratory and cardiac frequency, level of consciousness, respiratory arrest, diaphoresis and absence of lung sounds) and later course (length of hospital stay and mechanical ventilation, need for admission to the intensive care unit and adverse events during hospitalisation) showed no significant differences between groups. Finally, immunological studies showed that the NFA group without alexithymia showed a higher sensitisation rate to any allergen, as well as higher values of immunoglobulin E, a finding attributable to the lower mean age in this group. Spirometric data measured 3-5 weeks after hospital discharge were similar in both groups.

\section{DISCUSSION}

The term alexithymia was proposed in the 1970s by SIFNEOS [10] at the Beth Israel Hospital in Boston (MA, USA). Translated literally from the Greek, it means "a lack of words to express one's feelings". In practice, alexithymic individuals show a reduction in, or the absence of, symbolic thought, a limited ability to fantasise and difficulty in expressing their feelings in words [21] and in identifying physical sensations, such as pain or dyspnoea. Additional characteristics include a high degree of social conformity, stereotyped interpersonal relationships, difficulties in the expression of conflicts and an immature personality [21, 22]. The present results are in agreement with previous findings relating the prevalence of alexithymia to older age and lower levels of education, and possibly to an intellectual limitation in verbalising feelings and physical sensations [23, 24]. The influence of sex is not well established, although it appears to be more prevalent in males [25]. Studies such as that of KAUHANEN et al. [26] have shown the relevance of alexithymia as an element of comorbidity. Alexithymia in 2,297 middle-aged males, studied over a period of $5.5 \mathrm{yrs}$, was associated with twice the risk of mortality of that found in nonalexithymic patients. The relationship was unchanged after adjustment for potential confounding factors such as age, marital status, socio-economic level, health risk behaviour (smoking, alcohol consumption and sedentary lifestyle), cardiovascular risk factors (obesity, dyslipidaemia and hypertension), prior diagnosis of illnesses and presence of symptoms of depression (odds ratio 1.54 (95\% CI 1.01-2.36); $\mathrm{p}<0.05)$. Despite these findings, it is not known how alexithymia is related to somatic diseases, although it has been suggested that this trait may lead to inappropriate models of behaviour, which give rise to chronic diseases [27].

As in previous studies on chronic diseases, such as arterial hypertension, ulcerative colitis and Crohn's disease, renal failure and several psychiatric disorders (anxiety, depression and schizophrenia) $[11,28]$, the present study shows a higher incidence of alexithymia among NFA patients than in the general population. However, most of these studies and others conducted in asthma and chronic respiratory patients $[29,30]$ used questionnaires developed in the 1970s, such as the Beth Israel Hospital Psychosomatic Questionnaire or the Minnesota Multiphasic Personality Inventory alexithymia scale, which have weaker psychometric properties than the TAS questionnaire [31]. The higher proportion of alexithymia observed in NFA patients $(36 \%)$ than non-NFA patients $(13 \%)$ in the present study has not been previously described, and may suggest that alexithymia plays a role in NFA.

The influence of alexithymia in clinical settings requiring urgent medical attention, such as in a severe asthma exacerbation or acute myocardial infarction (AMI), has been analysed 
TABLE 2 Demographic, clinical and psychological characteristics of near-fatal asthma (NFA) patients by presence or absence of alexithymia

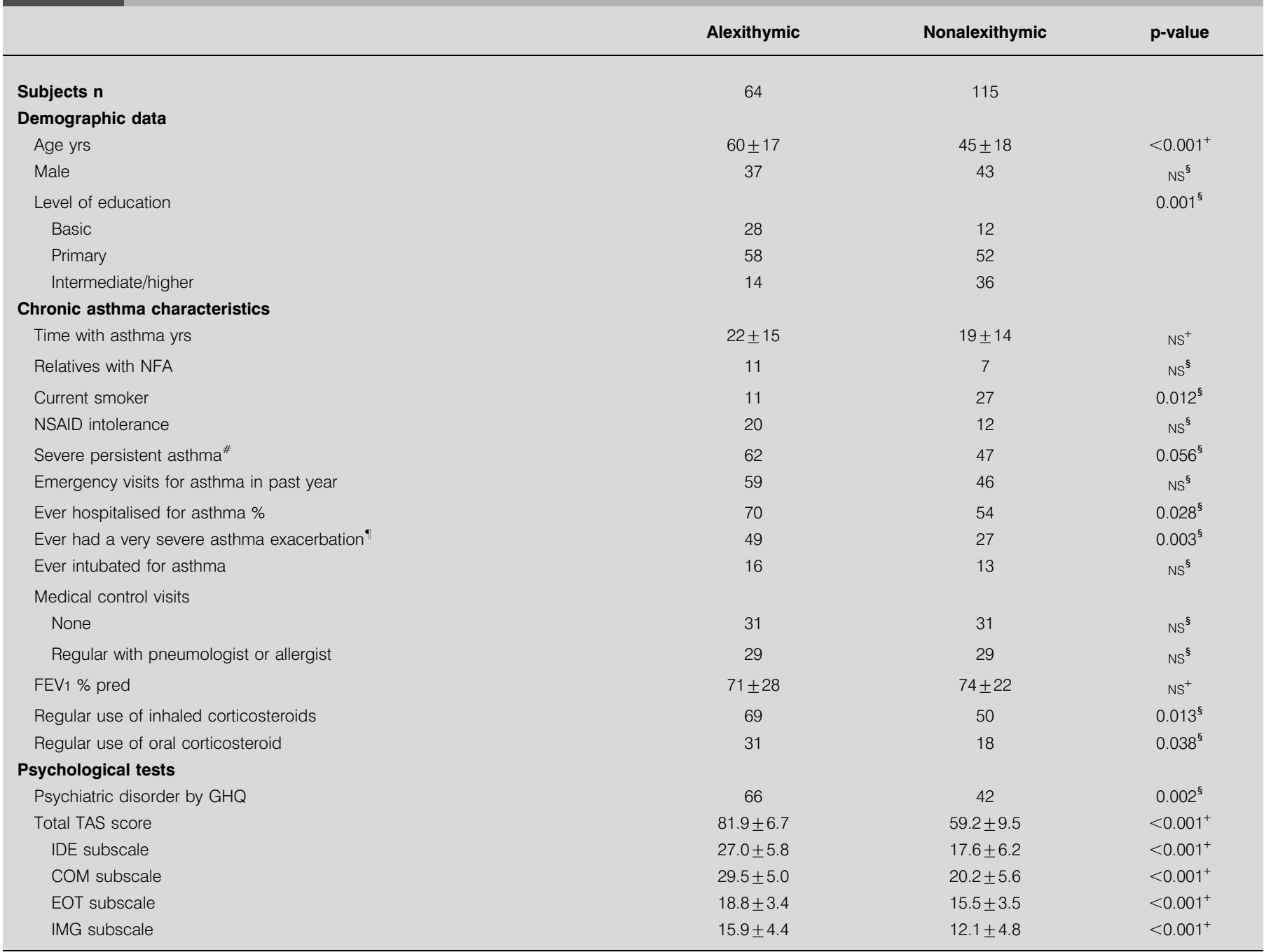

Data are presented as mean \pm SD or percentage. NSAID: nonsteroidal anti-inflammatory drug; FEV1: forced expiratory volume in one second; \% pred: percentage of the predicted value; GHQ: General Health Questionnaire [19]; TAS: Toronto Alexithymia Scale [17]; IDE: difficulty identifying feelings; COM: difficulty communicating feelings; EOT: externally oriented thinking; IMG: capacity to fantasise; NS: nonsignificant. *: Global Initiative for Asthma (GINA) classification [16]; ': involving mechanical ventilation, respiratory failure $(\mathrm{pH}<7.30$ and/or arterial carbon dioxide tension $>6.65 \mathrm{kPa}(>50 \mathrm{mmHg}))$ or intensive care unit admission; ${ }^{+}$: unpaired t-test; ${ }^{\S}$ : Chisquared test.

by other authors. BROwn et al. [12] studied 270 asthmatics during a severe attack, and, after adjusting for age, they observed that alexithymic asthmatics gave significantly lower scores for nine symptom/sign categories on the Asthma Symptom Checklist scale: panic-fear, irritability, fatigue, dyspnoea, thoracic oppression, worry, anger, loneliness, and tachypnoea. The authors interpreted these results as evidence that alexithymic individuals underestimate both physical and emotional components of asthma exacerbations, independently of the prior severity of the disease, and strongly recommended the use of objective methods for evaluating the severity of asthma attacks. Surprising similarities have been found between AMI and asthma. Alexithymic AMI patients are also reported to show blunted perception in recognising AMI symptoms [32], and delay seeking medical attention [33]. Conversely, some authors have found a positive correlation between one TAS subscale score (IDE) and a higher score for self-reporting of asthma symptoms. They also observed a negative correlation between spirometric data and another TAS subscale score (COM) [34]. The authors of this study interpreted this as meaning that difficulty in both identifying and communicating feelings may be detrimental for asthma control, operating in different ways. The relationship between the IDE subscale and the symptom report could be, in their opinion, mediated by trait anxiety. The difficulty in communicating asthma symptoms to physicians, conversely, could lead to suboptimal control of asthma, and may increase the risk of asthma exacerbation. However, these correlations were 


\begin{tabular}{|c|c|c|c|c|}
\hline \multirow[t]{2}{*}{ TABLE 3} & \multicolumn{4}{|c|}{$\begin{array}{l}\text { Factors involved in previous incidence of very } \\
\text { severe asthma exacerbations, after adjusting for } \\
\text { age, sex and presence of psychiatric morbidity }\end{array}$} \\
\hline & & OR & $95 \% \mathrm{Cl}$ & p-value \\
\hline \multicolumn{4}{|c|}{ Level of education } & 0.017 \\
\hline Primary & & 0.261 & $0.101-0.672$ & \\
\hline Intermediate & and higher & 0.509 & $0.171-1.516$ & \\
\hline \multicolumn{5}{|c|}{ Severe persistent asthma versus } \\
\hline \multicolumn{2}{|c|}{$\begin{array}{l}\text { moderate, mild and intermittent } \\
\text { asthma }^{+}\end{array}$} & 4.186 & $1.923-9.11$ & $<0.001$ \\
\hline \multicolumn{2}{|c|}{ Presence of alexithymia } & 2.175 & $1.002-4.721$ & 0.049 \\
\hline
\end{tabular}

found in asthmatics in stable clinical condition, not during an exacerbation. Thus, it is difficult to extrapolate the meaning of these findings for an asthma attack.

In the present study, no significant differences between the alexithymic and nonalexithymic NFA groups were observed regarding clinical variables, such as respiratory and cardiac frequency at admission, absence of lung sounds or presence of diaphoresis. Neither were there differences between groups in the delay in seeking hospital care or the means of transport used. These surprising results do not seem to confirm the hypothesis that alexithymia could lead to a delay in seeking medical attention during an asthma exacerbation. There is no clear explanation for this finding. However, the NFA asthmatics enrolled in the present study were highly familiarised with severe asthma attacks. Of these patients, $70 \%$ had previously been hospitalised for asthma exacerbations. Hypothetically, this earlier experience could give them, or their relatives, the ability to respond more appropriately in later attacks. An alternative explanation, consistent with the findings of FELDMAN et al. [34], could be that some alexithymics (those with high IDE subscale scores) respond differently from other alexithymics, and express more asthma symptoms when experiencing an asthma exacerbation. This possibility is very difficult to establish with the present data. Unfortunately, the designs of the present study and that of FELDMAN et al. [34] were very different. The present study did not collect selfreported asthma symptoms, and it must be remembered that $45 \%$ of the present cases showed impaired consciousness on hospital admission, so correlations between perceptions and IDE scores cannot be established. Moreover, as mentioned previously, FELDMAN et al. [34] studied patients in stable clinical condition, not during a very severe exacerbation, a difference that could be significant.

In the present study, more need for mechanical ventilation and more intense gasometric impairment (at least statistically) were also observed in the nonalexithymic group of NFA patients. The clinical meaning of this finding is uncertain, but the observation is consistent with the absence of worse clinical status of alexithymic asthmatics upon arrival at hospital (table 4) compared with the nonalexithymic group. The present authors do not have a solid explanation for this result.
TABLE 4 Characteristics of the near-fatal asthma (NFA) episode of patients according to presence or absence of alexithymia

Alexithymic Nonalexithymic p-value

\begin{tabular}{|c|c|c|c|}
\hline Subjects $\mathrm{n}$ & 64 & 115 & \\
\hline \multicolumn{4}{|l|}{ Suspected trigger } \\
\hline Unknown & 41 & 50 & NS \\
\hline Respiratory infections & 38 & 30 & NS \\
\hline NSAID & 6 & 7 & NS \\
\hline Fumes inhaled & 6 & 4 & NS \\
\hline Psychosocial stress & 3 & 2 & NS \\
\hline \multicolumn{4}{|l|}{$\begin{array}{l}\text { Observations on hospital } \\
\text { admission }\end{array}$} \\
\hline Pre-hospital delay min & $118(2-2880)$ & $130.5(0-2880)^{\bullet}$ & NS \\
\hline $\begin{array}{l}\text { Transportation by } \\
\text { ambulance }\end{array}$ & 42 & 55 & NS \\
\hline $\begin{array}{l}\text { Self-admission to } \\
\text { hospital }\end{array}$ & 53 & 43 & NS \\
\hline Respiratory arrest & 24 & 34 & NS \\
\hline $\begin{array}{l}\text { Absence of lung } \\
\text { sounds }\end{array}$ & 52 & 43 & NS \\
\hline Diaphoresis & 78 & 66 & NS \\
\hline $\begin{array}{l}\text { Impaired consciousness } \\
\text { level }\end{array}$ & 41 & 48 & NS \\
\hline $\begin{array}{l}\text { Tracheal intubation } \\
\text { required }\end{array}$ & 39 & 57 & 0.025 \\
\hline $\begin{array}{l}\text { Respiratory frequency } \\
\text { breaths } \cdot \min ^{-1}\end{array}$ & $33 \pm 9$ & $32 \pm 10$ & NS \\
\hline $\begin{array}{l}\text { Cardiac frequency } \\
\text { beats } \cdot \mathrm{min}^{-1}\end{array}$ & $112 \pm 16$ & $118 \pm 20$ & NS \\
\hline $\mathrm{pH}$ & $7.21 \pm 0.12$ & $7.16 \pm 0.17$ & 0.021 \\
\hline $\mathrm{PA}-\mathrm{a}, \mathrm{O}_{2}$ & $95 \pm 106$ & $95 \pm 114$ & NS \\
\hline $\mathrm{Pa}, \mathrm{CO}_{2} \mathrm{mmHg}$ & $64 \pm 20$ & $72 \pm 33$ & 0.051 \\
\hline \multicolumn{4}{|l|}{ Course } \\
\hline Time in hospital days & $10(1-35)$ & $9(1-76)$ & NS \\
\hline Time in ICU days & $1(0-24)$ & $2(0-46)$ & NS \\
\hline $\begin{array}{l}\text { Time under mechanical } \\
\text { ventilation } \mathrm{h}\end{array}$ & $24.5(3-528)$ & $20(1-888)^{+}$ & NS \\
\hline Complications & 25 & 27 & NS \\
\hline \multicolumn{4}{|l|}{ Immunological studies } \\
\hline $\begin{array}{l}\text { Positive skin-prick } \\
\text { test }\end{array}$ & 41 & 65 & 0.003 \\
\hline \multicolumn{4}{|l|}{$\begin{array}{l}\text { Spirometry after } \\
\text { hospitalisation }\end{array}$} \\
\hline FEV1 pred & $72 \pm 24$ & $77 \pm 24$ & NS \\
\hline$\Delta \mathrm{FEV} 1$ post-BD ${ }^{\#}$ & $8.9 \pm 8.1$ & $9.7 \pm 10.3$ & NS \\
\hline
\end{tabular}

Data are presented as mean $\pm \mathrm{SD}$, median (interquartile range) or percentages Percentages are of cases. NSAID: nonsteroidal anti-inflammatory drug; $P A-a, \mathrm{O}_{2}$ : alveolar-arterial oxygen tension difference; $\mathrm{Pa}_{\mathrm{a}} \mathrm{CO}_{2}$ : arterial carbon dioxide tension; ICU: intensive care unit; FEV1: forced expiratory volume in one second; $\%$ pred: percentage of the predicted value; $\Delta$ : change (increase); post-BD: post-bronchodilator (salbutamol); Ns: nonsignificant. * : (post-BD FEV1-pre-BD FEV1)/reference FEV 1 ; ${ }^{\bullet}$ : one began when the patient was in the hospital ward; +: calculated only in patients requiring mechanical ventilation. $1 \mathrm{mmHg}=$ $0.133 \mathrm{kPa}$. 
Perhaps, alexithymia could play a role in NFA, not specifically during the asthma attack but rather when a patient with chronic severe asthma is in the normal clinically stable condition. The difficulty that alexithymic asthma patients have in recognising body sensations and emotional perceptions could lead to poorer asthma control in general, not only during exacerbations. As a result, they could suffer more severe asthma attacks (including NFA episodes) than nonalexithymic asthma patients do. Indeed, it is possible that some asthma exacerbations could go unrecognised by them. Probably, a specific study monitoring pulmonary function before, as well as during, an asthma attack in alexithymic patients could be useful for clarifying the reasons for the observed pattern.

The main finding of the present study was the high proportion (49\%) of alexithymic patients with a current NFA episode who had suffered a very severe asthma exacerbation previously. This was significantly higher than in the nonalexithymic NFA patients $(27 \%)$. This result may have several explanations. Some authors have suggested that alexithymia could interfere with the medical control of asthma. DIRKS et al. [30] found a greater frequency of asthma-induced recurrent hospitalisation in alexithymic patients (37.4 versus $28.4 \%$ over 6 months), and suggested that their difficulty in expressing the intensity and frequency of symptoms could lead physicians to underestimate the severity of their asthma. As a result, treatment may be insufficient to control their disease. However, the results of the present study show that alexithymic patients received more inhaled and oral corticosteroids than nonalexithymic patients. Studies of other diseases, such as ischaemic heart disease, have also shown a higher proportion of alexithymics among patients with prior severe crises. The study of KoJIMA et al. [35], conducted in 1,443 cardiac patients, showed a higher percentage of patients with prior episodes of AMI among alexithymics $(19 \% ; p=0.04)$. These authors suggested that "secondary alexithymia" might develop as a consequence of repeated stressful situations, such as AMI. Whether alexithymia is a cause or a consequence of recurrent episodes of NFA or AMI, once alexithymia improves, the clinical course of some patients also improves. Over a 2-yr follow-up study, BERESNEVAITE [36] observed that AMI patients whose TAS scores improved after psychotherapy suffered fewer new infarctions, sudden deaths and hospital admissions for angor pectoris and arrhythmia (18\%) than the group that maintained the same TAS scores (67\%). An improvement in alexithymic levels following psychotherapeutic interventions in patients with inflammatory bowel disease has also been previously reported [37].

In conclusion, the present study shows that alexithymia is frequent in near-fatal asthma patients, and also that it appears to be related to recurrent very severe asthma exacerbations. This could have implications in clinical practice. Taking into account the favourable results with psychotherapy in other illnesses, prospective studies should be designed to investigate the possible role of such treatment in reducing recurrence of very severe asthma attacks in alexithymic patients. Affirmative results would provide a new therapeutic tool, not considered to date, specific to this group of near-fatal asthma patients.

\section{ACKNOWLEDGEMENTS}

The authors wish to thank J. Lewis (Barcelona, Spain) and M.E. Kerans (Universitat Internacional de Catalunya, Barcelona, Spain) for assistance with the manuscript, and I. Gich (Clinical Epidemiology Dept, Hospital de la Santa Creu i de Sant Pau, Barcelona, Spain) for help in the statistical analyses.

Spanish High Risk Asthma Research Group Scientific Committee: S. Bardagí (Consorci Hospitalari de Mataró, Mataró), A. de Diego (Hospital La Fe, Valencia), A. LópezViña (Hospital Cabueñes, Gijón), J. de Pablo (Hospital Clinic, Barcelona), E.G. Pérez-Yarza (Hospital de Aranzazu, San Sebastián), C. Picado (Hospital Clinic, Barcelona), V. Plaza (Hospital de Sant Pau, Barcelona), J. Sanchis (Hospital de Sant Pau, Barcelona), and J. Serrano (Hospital de Sant Pau, Barcelona).

Members of Spanish High Risk Asthma Research Group: J. Abad (Hospital Cristal-Piñor, Orense), J. Ancochea (Hospital de la Princesa, Madrid), J. Armengol (Hospital de Terrassa, Terrassa), S. Bardagí (Consorci Hospitalari de Mataró, Mataró), J. Barrio (Hospital de Sierrallana, Torrelavega), J.M. Benítez (Hospital Universitario Virgen de la Macarena, Seville), J. Botey (Hospital Vall d'Hebron, Barcelona), E. Chacón (Hospital Miguel Server, Saragossa), N. Cobos (Hospital Vall d'Hebron, Barcelona), F.J. Cosano (Hospital Reina Sofía, Córdoba), A. de Diego (Hospital La Fe, Valencia), A. Escribano (Hospital Clínico Universitario, Valencia), J.B. Gáldiz (Hospital de Cruces, Biscay), G. García-Hernandez (Hospital 12 de Octubre, Madrid), I. González- Martín (Hospital Universitario de Canarias, La Laguna), J.L. Heredia (Hospital Mútua de Terrassa, Terrassa), J. Izquierdo (Hospital Germans Trias i Pujol, Badalona), J. Korta (Hospital del Bidasoa, Hondarribia), J. Lamela (Hospital Cristal-Piñor, Orense), A. López-Viña (Hospital Cabueñes, Gijón), P. Martín Escribano (Hospital 12 de Octubre, Madrid), J.J. MartínVillasclaras (Hospital Carlos Haya, Málaga), E. MartínezMoragón (Hospital de Sagunto, Sagunto), R. Melchor (Fundación Jiménez Díaz, Madrid), J.M. Merino (Hospital Guipúzcoa, San Sebastián), J. de Pablo (Hospital Clinic, Barcelona), C. Pellicer (Hospital Francesc de Borja, Gandía), E.G. Pérez-Yarza (Hospital de Aranzazu, San Sebastián), M. Perpiñá (Hospital La Fe, Valencia), C. Picado (Hospital Clinic, Barcelona), C. Planell (Hospital Dr. Josep Trueta, Gerona), V. Plaza (Hospital de Sant Pau, Barcelona), J. Ramos (Hospital Galdakao, Galdakao), R. Sánchez-Gil (Hospital Universitario Virgen del Rocío, Seville), J. Sanchis (Hospital de Sant Pau, Barcelona), J. Serra (Hospital General de Vic, Vic), J. Serrano (Hospital de Sant Pau, Barcelona), and B. Sureda (Hospital Clinic, Barcelona).

\section{REFERENCES}

1 Molfino NA, Slutsky AS. Near-fatal asthma. Eur Respir J 1994; 7: 981-990.

2 Strunk RC. Identification of the fatality-prone subject with asthma. J Allergy Clin Immunol 1989; 83: 477-485.

3 Campbell DA, McLennan G, Coates JR, et al. A comparison of asthma deaths and near fatal asthma attacks in South Australia. Eur Respir J 1994; 7: 490-497.

4 Johnson AJ, Nunn AJ, Somner AR, Stableforth DE, Stewart CJ. Circumstances of death from asthma. BMJ 1984; 288: 1870-1872. 
5 Kikuchi Y, Okabe S, Tamura G, et al. Chemosensitivity and perception of dyspnea in patients with a history of nearfatal asthma. N Engl J Med 1994; 330: 1329-1334.

6 Magadle R, Berar-Yanay N, Weiner P. The risk of hospitalization and near fatal and fatal asthma in relation to the perception of dyspnea. Chest 2002; 121: 329-333.

7 Boulet LP, Deschesnes F, Tourcotte H, Gignac F. Near fatal asthma: clinical and physiologic features, perception of bronchoconstriction and psychologic profile. J Allergy Clin Immunol 1991; 88: 838-846.

8 Campbell DA, Yellowlees PM, McLennan G, et al. Psychiatric and medical features of near fatal asthma. Thorax 1995; 50: 254-259.

9 Banzett RB, Dempsey JA, O'Donnell DE, Wamboldt MZ. Symptom perception and respiratory sensation in asthma. Am J Respir Crit Care Med 2000; 162: 1178-1182.

10 Sifneos PE. The prevalence of "alexithymic" characteristics in psychosomatic patients. Psychother Psychosom 1973; 22: 255-262.

11 Sivak R, Wiater A. Investigaciones clínicas. Clinical investigations.] In: Sivak R, Wiater A, eds. Alexitimia, la Dificultad para Verbalizar Afectos. Teoría y Clínica. [Alexithymia, the Difficulty to Verbalise Affections. Theory and Practice.] Buenos Aires, Paidós SAICF, 1997; pp. 55-69.

12 Brown EL, Fukuhara JT, Feiguine RJ. Alexithymic asthmatics: the miscommunication of affective and somatic states. Psychother Psychosom 1981; 36: 116-121.

13 Serrano J, Plaza V, Picado C, Sanchis J. Alexithymia and near-fatal asthma. Results of the Spanish near-fatal asthma multicentric study. Eur Respir J 2000; 16: Suppl. 31, 153s.

14 Plaza V, Serrano J, Picado C, Sanchis J. Frequency and clinical characteristics of rapid-onset fatal and near-fatal asthma. Eur Respir J 2002; 19: 846-852.

15 American Thoracic Society. Standards for the diagnosis and care of patients with chronic obstructive pulmonary disease (COPD) and asthma. Am Rev Respir Dis 1987; 136: 225-244.

16 Global Initiative for Asthma. Global Strategy for Asthma Management and Prevention. NHLBI/WHO workshop report. Publication No. 95-3659. Bethesda, MD, National Institutes of Health, National Health, Lung and Blood Institute, 1995.

17 Taylor GJ, Ryan D, Bagby RM. Toward the development of a new self-report alexithymia scale. Psychother Psychosom 1985; 44: 191-199.

18 Rodrigo G, Lusiardo M, Normey L. Alexithymia: reliability and validity of the Spanish version of the Toronto Alexithymia Scale. Psychother Psychosom 1989; 51: 162-168.

19 Goldberg D. Use of the general health questionnaire in clinical work. BMJ 1986; 293: 1188-1189.

20 Lobo A, Pérez Echeverria MJ, Artal J. Validity of scaled version of the General Health Questionnaire (GHQ-28) in a Spanish population. Psychol Med 1986; 16: 135-140.

21 Sivak R, Wiater A. Teoría y clínica de la alexitimia. [Theory and clinics for alexithymia.] In: Sivak R, Wiater A, eds. Alexitimia, la Dificultad para Verbalizar Afectos. Teoría y Clínica. [Alexithymia, the Difficulty to Verbalise Affections. Theory and Practice.] Buenos Aires, Paidós SAICF, 1997; pp. 17-33.
22 Bagby M, Taylor G. Affect dysregulation and alexithymia. In: Taylor GJ, Bagby RM, Parker JDA, eds. Disorders of Affect Regulation. Alexithymia in Medical and Psychiatric Illness. Cambridge, Cambridge University Press, 1997; pp. 26-45.

23 Pasini A, Delle Chiaie R, Seripa S, Ciani N. Alexithymia as related to sex, age and educational level: results of the Toronto Alexithymia Scale in 417 normal subjects. Compr Psychiatry 1992; 33: 42-46.

24 Kauhanen J, Kaplan GA, Julkunen J, Wilson TW, Salonen JT. Social factors in alexithymia. Compr Psychiatry 1993; 34: 330-335.

25 Kokkonen P, Karvonen JT, Veijola J, et al. Prevalence and sociodemographic correlates of alexithymia in a population sample of young adults. Compr Psychiatry 2001; 42: 471-476.

26 Kauhanen J, Kaplan GA, Cohen RD, Julkunen J, Salonen JT. Alexithymia and risk of death in middle-aged men. $J$ Psychosom Res 1996; 41: 541-549.

27 Lumley MA, Stettner L, Wehmer F. How are alexithymia and physical illness linked? A review and critique of pathways. J Psychosom Res 1996; 41: 505-518.

28 Taylor G. Affects and alexithymia in medical illness and disease. In: Taylor GJ, Bagby RM, Parker JDA, eds. Disorders of Affect Regulation. Alexithymia in Medical and Psychiatric Illness. Cambridge, Cambridge University Press, 1997; pp. 216-247.

29 Kleiger JH, Jones NF. Characteristics of alexithymic patients in a chronic respiratory illness population. J Nerv Ment Dis 1980; 168: 465-470.

30 Dirks JF, Robinson SK, Dirks DL. Alexithymia and the psychomaintenance of bronchial asthma. Psychother Psychosom 1981; 36: 63-71.

31 Taylor GJ, Bagby RM. Measurement of alexithymia. Recommendations for clinical practice and future research. Psychiatr Clin North Am 1988; 11: 351-366.

32 Theisen ME, MacNeill SE, Lumley MA, Ketterer MW, Goldberg AD, Borzak S. Psychosocial factors related to unrecognized acute myocardial infarction. Am J Cardiol 1995; 75: 1211-1213.

33 Kenyon LW, Ketterer MW, Gheorgiade M, Goldstein S. Psychological factors related to prehospital delay during acute myocardial infarction. Circulation 1991; 84: 1969-1976.

34 Feldman JM, Lehrer PM, Hochron SM. The predictive value of the Toronto Alexithymia Scale among patients with asthma. J Psychosom Res 2002; 53: 1049-1052.

35 Kojima M, Frasure-Smith N, Lespérance F. Alexithymia following myocardial infarction: psychometric properties and correlates of the Toronto Alexithymia Scale. J Psychosom Res 2001; 51: 487-495.

36 Beresnevaite M. Exploring the benefits of group psychotherapy in reducing alexithymia in coronary heart disease patients: a preliminary study. Psychother Psychosom 2000; 69: 117-122.

37 Freyberger H, Kunsebeck HW, Lempa W, Wellmann W, Avenarius HJ. Psychotherapeutic interventions in alexithymic patients. With special regard to ulcerative colitis and Crohn patients. Psychother Psychosom 1985; 44: 72-81. 